\title{
Genomic and epigenomic alterations in prostate cancer
}

\section{Anna M. Aschelter, Silvana Giacinti, Paola Caporello and Paolo Marchetti*}

Department of Oncology, Sant'Andrea Hospital, "Sapienza" University of Rome, Rome, Italy

\section{Edited by:}

Carmen Priolo, Brigham and Women's Hospital, Harvard Medical School,

USA

\section{Reviewed by:}

Daniela Pasquali, Seconda Università degli Studi di Napoli, Italy

Alberto Ferlin, University of Padova, Italy

Emanuele Palescandolo, Janssen

Pharmaceutica, Belgium

\section{*Correspondence:}

Paolo Marchetti, Department of Oncology, Sant'Andrea Hospital,

"Sapienza" University of Rome,

Via di Grottarossa 1035-1039,

00189 Rome, Italy.

e-mail: paolo.marchetti@

ospedalesantandrea.it
Prostate cancer $(\mathrm{PC})$ is the second most frequently diagnosed cancer and the second leading cause of cancer deaths in man. The treatment of localized PC includes surgery or radiation therapy. In case of relapse after a definitive treatment or in patients with locally advanced or metastatic disease, the standard treatment includes the androgen-deprivation therapy (ADT). By reducing the levels of testosterone and dihydrotestosterone under the castration threshold, the ADT acts on the androgen receptor (AR), even if indirectly. The effects of the ADT are usually temporary and nearly all patients, initially sensitive to the androgen ablation therapy, have a disease progression after an 18-24 months medium term. This is probably due to the selection of the cancer cell clones and to their acquisition of critical somatic genome and epigenomic changes. This review aims to provide an overview about the genetic and epigenetic alterations having a crucial role in the carcinogenesis and in the disease progression toward the castration resistant PC. We focused on the role of the AR, on its signaling cascade and on the clinical implications that the knowledge of these aspects would have on hormonal therapy, on its failure and its toxicity.

Keyword: prostate cancer

\section{INTRODUCTION}

Prostate cancer (PC) is the second most frequently diagnosed cancer and the second leading cause (the first one is lung cancer) of cancer deaths in man. The estimate of new diagnoses and deaths from PC in 2012, in the United States, amounted to 241,740 and 28,170, respectively (American Cancer Society, 2012). In Italy, it has been estimated that every year 23,518 new PCs are diagnosed; deaths due to PC are 7,105 (AIRT, 1998-2002). PC incidence and mortality displays geographic variation, with high rates of incidence and mortality in the US and Western Europe, and low rates in Asia (Makridakis et al., 1997; Figure 1).

Data show that mortality from PC is relatively lower compared to the total number of yearly diagnosed cases. Therefore most patients die with this disease rather than from it (Nelson et al., 2008). The treatment of localized PC includes surgery or radiation therapy. In cases of relapse after a definitive treatment or in patients with locally advanced (T3b to T4) or metastatic disease (N1 or $\mathrm{M} 1$ ), the standard treatment includes the androgen-deprivation therapy (ADT; Huggins and Hodges, 2002). The ADT aims to reduce the circulating levels of testosterone around or below levels present in castration $(<50 \mathrm{ng} / \mathrm{ml})$. The reason behind the use of hormone therapy in the PC treatment is that the tumor growth is initially dependent on androgens. Androgens stimulate the tumor cells proliferation and inhibit their apoptosis. Conversely, ADT reverses the equilibrium in favor of the second one (Figure 2).

The androgen deprivation $(\mathrm{AD})$ can be achieved by the use of LHRH analogs (medical castration) or bilateral orchiectomy (surgical castration). Through the circulating levels of testosterone and dihydrotestosterone (DHT) reduction, the ADT indirectly affects the androgen receptor (AR), which represents the real target of this therapy. The androgen biosynthesis consists in a multi-step process taking place in man's gonads and adrenals and in which many enzymes are involved. Cytochrome P450c17 $\alpha$, with both
$17 \alpha$-hydroxylase and 17,20-lyase activity, has a key role among these proteins (Figure 3 ).

The testosterone is the primary circulating androgen in man, chiefly produced by Leydig cells in the testes and converted to DHT in prostate cells by the enzyme 5-alpha-reductase (Figure 4; Steers, 2001).

The androgen DHT is more active having a fivefold higher affinity than testosterone for the AR. The androgen signal blockade kills PC cells through the induction of a programed cellular death. The effects of ADT are usually temporary and nearly all patients, initially sensitive to the androgen ablation therapy, have a disease progression after a 18-24 months medium term (Crawford, 1992). This probably results from the cancer cell clones selection, generated by the acquisition of critical somatic genome changes. Castration resistant PC (CRPC) is a lethal form of PC defined as a tumor which develops in spite of very low levels of androgens (below the threshold that defines castration). Preclinical investigation has led to advances in the understanding of the molecular basis of the CRPC. Various mechanisms have been proposed to explain how the tumor becomes able to maintain an incentive to grow in spite of very low serum levels of testosterone. This review aims to provide an overview about the genetic and epigenetic alterations having a crucial role in the carcinogenesis and in the disease progression, toward a more aggressive phenotype (Ruijter et al., 1999; Feldman and Feldman, 2001). In particular, we focused on the role of the AR, on its signaling cascade and the on its clinical implications that the knowledge of these aspects would have on the hormonal therapy, on its failure and toxicity.

\section{GENOMIC ALTERATIONS}

Genomic alterations with a potential involvement in PC include somatic mutations, gene deletions or amplifications, chromosomal rearrangements. In the natural history of PC these alterations 


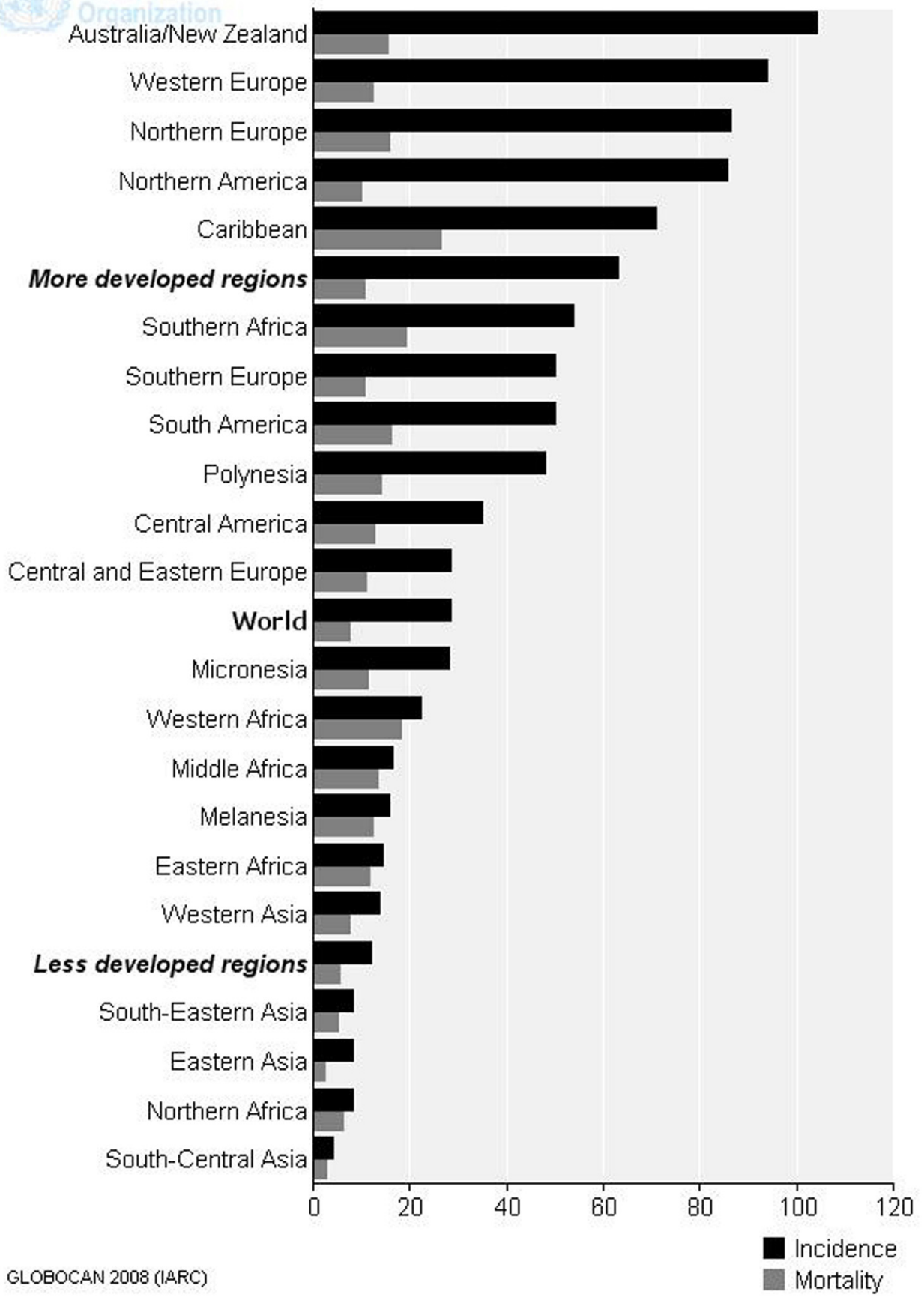

FIGURE 1 | Age-standardized rates (world) per 100,000 of PC in 2008 (data from Ferlay et al., 2010).

are probably accumulated over a period of several decades. The first studies on the molecular changes, with a potential crucial role in the development of PC, have identified chromosomal abnormalities frequently reported in PC patients, such as the gain of genetic material in $7 \mathrm{p}, 7 \mathrm{q}, 8 \mathrm{q}$, and $\mathrm{Xq}$ and losses in $8 \mathrm{p}$ (Helcomb et al., 2009), 10q, 13q, and 16q. Some studies have shown that a chromosomal translocation involving TMPRSS2 (PSA-regulated gene transmembrane protease, serine 2), an androgen-responsive gene and a member of the ETS family of transcription factors (ERG, ETV1, ETV4, or ETV5) is present in over $60 \%$ of localized 


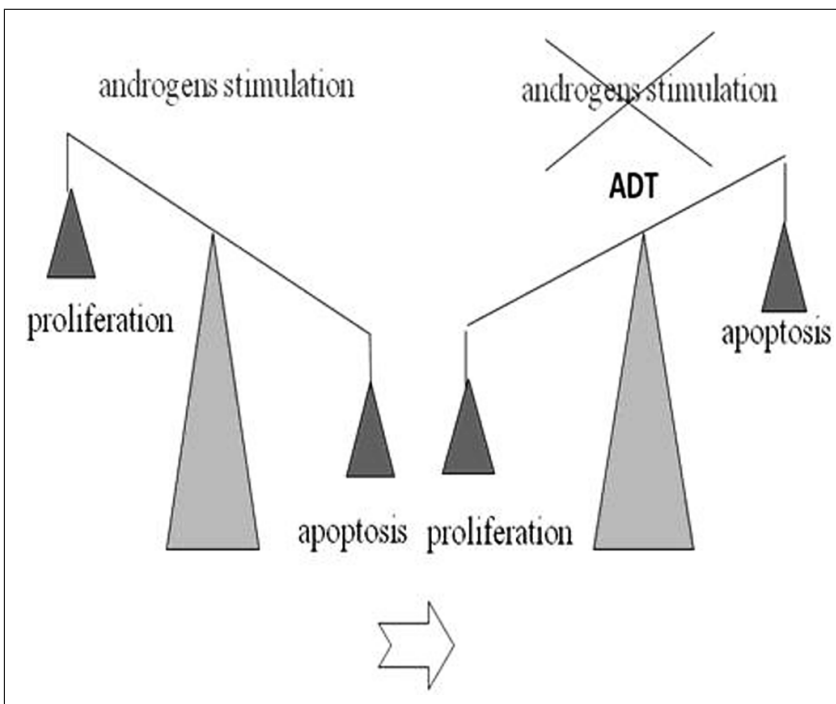

FIGURE 2 |Androgen-deprivation therapy (ADT) effect on proliferation/ apoptosis PC cells: androgens stimulate the tumor cells proliferation and inhibit their apoptosis. ADT reverses the equilibrium in favor of the apoptosis.

and metastatic prostate tumors and in $20 \%$ of PIN (Tomlins et al., 2005). ETS proteins cooperate with other transcription factors in the regulation of various cellular functions such as proliferation, differentiation, angiogenesis, apoptosis, and carcinogenesis. The ERG gene is the most common fusion partner with TMPRSS2. The incidence of the TMPRSS2-ERG fusion is almost 60\% in PC. Both

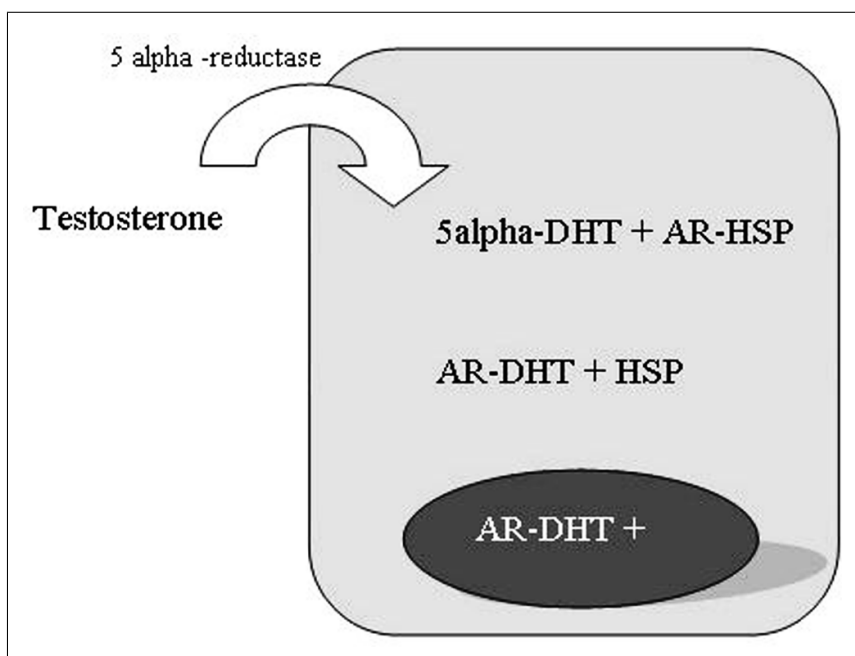

FIGURE 4 | 5-alpha-reductase activity in prostate cells.

genes are localized on chromosome $21 \mathrm{q} 22$ and the fusion takes place by an interstitial deletion. Translocations involving other ETS family members occur rarely. Seventeen different TMPRSS2ERG fusions, involving different regions of the TMPRSS and the ERG, have been identified. Eight of these fusions do not encode functioning ERG proteins for the introduction of a premature stop codon. Nine give rise to functional fusion products: two encode the normal ERG protein, six truncated ERG proteins, and one is a new protein resulting from the TMPRSS2 and the ERG fusion. The

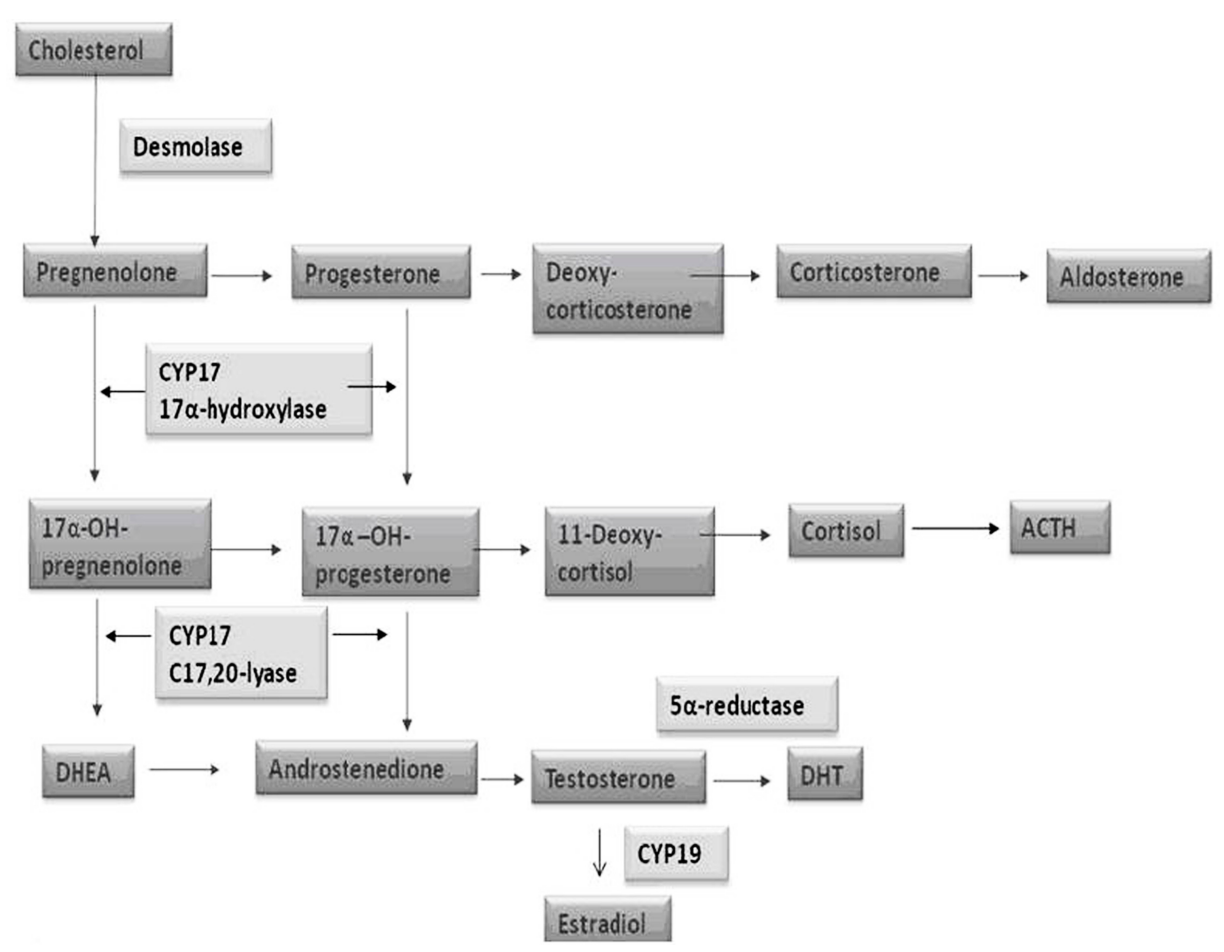

FIGURE 3 | Steroid biosynthesis. 
biological consequence of these different products is unknown. The TMPRSS-ERG translocation is considered an early event in the development of PC; it is not present in prostate benign lesions or hyperplasia. However, this is probably not the initial event as it is observed only in $20 \%$ of the PIN and it does not seem to have a direct role in the progression to adenocarcinoma. These data suggest that additional genetic mutations must occur. Aberrations were also identified in signal pathways of growth factors (NKX3.1, PTEN, c-MYC, and p27) and in the AR axis as determinants of the cancer cell phenotype. The $\mathrm{LOH}$ of $8 \mathrm{p} 21.2$ is found in $60 \%$ of the PIN and $85 \%$ of PC. The transcription factor NKX3.1 AR-regulated, whose normal function is to facilitate the terminal differentiation of prostatic epithelial cells, maps in this location. It has been suggested that the NKX3.1 is a gatekeeper tumor suppressor gene, similar to the APC in the colon cancer, to the VHL in renal clear cell carcinoma and to the $\mathrm{RB}$ in retinoblastoma. In contrast to peculiar tumor suppressor genes, however, allele of the NKX3.1 has not changed and the loss of heterozygosity determines a reduction of protein levels. The amplification of chromosome 8q24 associated to the over-expression of the transcription factor MYC is more frequently observed in PIN and in localized or metastatic PC. The decrease of p27, a cell cycle inhibitor, is correlated with an increase in histological grade of PC and with the risk of relapse. The $\mathrm{LOH}$ 12 q12-13 containing p 27 is present in 20\% of localized disease cases and in approximately $50 \%$ of metastatic disease (Mackinnon et al., 2009). Also, single-nucleotide polymorphisms (SNPs) in key genes have been hypothesized to be associated with PC risk, outcome, and responsiveness to therapies. With respect to this topic, a meta-analysis based on 38 studies involving 34,782 cases of PC and 38,626 controls, suggested that the SNP of the CYP17 gene, rs743572, may be significantly associated with the risk of PC in the Black population (but not in Caucasian and Asian; Wang et al., 2011). Wright et al. (2010) affirmed that men with genetic variants in the CYP17 may differ in responsiveness to drugs from the wild-type gene carriers. This may have critical effects in regulating response of PC to the new CYP17 inhibitors like the Abiraterone acetate.

\section{EPIGENOMIC ALTERATIONS}

Epigenetic changes are all the heritable changes in gene expression not resulting by alterations in the DNA sequence (Berger et al., 2009). The well-known epigenetic mechanisms are DNA methylation, changes to chromatin and alterations of microRNAs expression. Considerable evidences exist that a global DNA hypomethylation occurs late in PC contributing to the disease progression by promoting genomic instability (Chin et al., 2011). The inactivation of specific genes, caused by silencing their transcription through epigenetic alterations, is largely known as one of the mechanisms which can contribute to carcinogenesis. Among these epigenetic alterations in PC, the aberrant methylation of DNA in the promoter region of some genes (like GSTP - pi-class glutathione S-transferase) is a significant event (Lee et al., 1994). The somatic inactivation of the GSTP, which is a gene involved in detoxification, is the result of an aberrant methylation (hypermethylation) of CpG islands located in the gene promoter. As a result of this alteration the cells are more prone to accumulate additional mutations. This event seems to be involved in an early stage of the prostatic carcinogenesis: it is present in $70 \%$ of high-grade PIN and in more than $90 \%$ of adenocarcinomas (Nakayama et al., 2003; Kang et al., 2004). Li et al. (2001) observed that the degree of hypermethylation of E-cadherin gene (a gene in maintenance of normal cell architecture involved) in PC tissue was correlated with the pathological stage. They found an hypermethylation of Ecadherin gene promoter into the $30 \%$ of low-grade and the $70 \%$ of high-grade tumor tissues, respectively. Furthermore, hypermethylation of the p16 gene promoter results in a proliferative advantage of the cell clone so modified, with obvious implications, both in carcinogenesis and in the disease progression (Jarrard et al., 1997; Gu et al., 1998). In about $66 \%$ of PC the expression of the PTEN, an inhibitor of the PI3K/Akt pathway, is reduced or absent, with consequent activation of the PTEN/AKT/mTOR pathway. PTEN loss of function can result from deletion, mutation or epigenetic gene silencing. The PTEN epigenetic transcription silencing is often consequence of the $\mathrm{CpG}$ islands methylation located in its promoter region and would have a role in disease progression (Cairns et al., 1997; Suzuki et al., 1998). In some PC, the DNA hypermethylation could be also involved in the regulation of the AR expression. Suzuki et al. (2003) data showed that in 30\% of hormone-refractory PC, the expression of the AR may be lost as a result of the AR promoter gene hypermethylation. Similarly the hypomethylation and consequent upregulation of genes like heparanase, urokinase may contribute to tumor cell invasion and metastasis (Hulett et al., 1999; Pakneshan et al., 2003). More examples of genes frequently silenced in PC are the APC, the MGMT, and the MDR1 (Kang et al., 2004).

\section{CASTRATION RESISTANT PROSTATE CANCER AND AR}

The issue of androgen independence has been recently reviewed in light of the new knowledge achieved, so much so that today the term of resistance to castration is preferred. It is known that in the process of $\mathrm{PC}$ progression, the AR signaling axis maintains a decisive role: $\mathrm{PC}$ cells, once become resistant to castration, can evade the ADT cell growth inhibition and continue to express androgens-regulated genes even with castration serum levels of androgens. This should be partly explained by genetic alterations on the AR. As demonstrated in literature, AR alterations are observed in more than $50 \%$ of metastatic PC cases and tend to be rare in limited disease (Marcelli et al., 2000). It is yet unclear when the tumor acquires genetic alterations leading to castration resistance. While some studies suggest that tumor acquires these genetic alterations regardless of the ADT, other data highlight that the ADT would exert selective pressure on tumor cells. In this way the ADT would select cell clones able to grow independently from androgens, thanks to AR mutations (Taplin et al., 1995). The $\mathrm{AR}$ is a nuclear transcription factor whose gene belongs to the steroid-thyroid-retinoid nuclear receptor super-family. The AR gene is located on the $\mathrm{X}$ chromosome and contains eight exons. It encodes a protein of 919 amino acids. The AR is composed of four different domains: the N-terminal domain (NTD), the deoxyribonucleic acid-binding domain (DBD), the hinge region, and the ligand-binding domain (LBD; Lonergan and Tindall, 2011). AR aberrations correlated to the long-term failure of the ADT include the AR amplification/over-expression, the alternative source of androgens, the mutated AR or promiscuous AR, the 
over-expression of $\mathrm{AR}$ co-regulators, the $\mathrm{AR}$ activation by $\mathrm{CK}$ or growth factors. Nevertheless, the AR continues to be expressed even in disease advanced stages, regardless sensitivity to hormonal therapy (van der Kast et al., 1991; Hobisch et al., 1995).

\section{AR AMPLIFICATION/OVER-EXPRESSION}

The amplification of the AR gene has been associated with endocrine therapy failure. In a Finnish study on 54 patients, this specific alteration was found in about $30 \%$ of locally recurrent or metastatic hormone-refractory tumors, while absent in the untreated ones. Koivisto et al. (1997) concluded that AR amplifications occurs exclusively during the disease progression after the $\mathrm{ADT}$ and it is more frequent in tumors with an initial good response to the hormone therapy. Indeed, tumor cells in this case would be more critically dependent on androgen than in patients primarily resistant to ADT. Also, recurrent tumors with the AR gene amplification treated with a first-line hormonal monotherapy, could benefit from a second-line combined androgen blockade, more than patients without this AR alteration, although this does not mean a gain in survival (Palmberg et al., 2000). Gregory et al. (2004) also confirms that the basis of castration resistance may consist in an hypersensitivity of the AR, resulting from its over-expression, increased stability and intranuclear localization.

\section{ALTERNATIVE SOURCE OF ANDROGENS}

In spite of extremely low levels of circulating androgens, the CRPC progression remains dependent on the androgen-driven activity and PC cells keep the AR pathway active in different ways. An hypothesis standing to explain this observation is that alternative sources of androgenic steroids exist. Pioneer works, confirmed by recent researches in this area, indicated that intraprostatic amount of testosterone and DHT remains moderately high despite their castration serum levels (Liu et al., 1985; Labrie, 2004; Titus et al., 2005). Locke et al. (2008) hypothesized that androgens de novo synthesized within prostatic tumor tissue may drive the CRPC progression in the absence of testicular androgens. Also they argue that some enzymes necessary for androgens synthesis (SRD5A1, $\mathrm{RDH} 5, \mathrm{ARK} 1 \mathrm{C} 1,2,3)$ are up-regulated in PC cells during the CRPC progression. Montgomery et al. (2008) remarked this theory showing that all the enzymes involved in the biosynthesis of testosterone and DHT were expressed in the majority of metastatic CRPC examined in his study. This would explain how the decrease of DHT in prostate tissue after the ADT may not be proportional to decreased levels of circulating testosterone (60 vs. $95 \%$ respectively; Labrie et al., 1986). What also appears to be assumed is that the adrenal steroids peripheral conversion may be sufficient to the maintain androgen signal, resulting in the tumor growth and in the ADT failure. This is the rationale behind the use of the combination therapy with antiandrogen plus LHRH analog and the basis for use of CYP17 inhibitors like ketoconazole (use limited by its toxicity; Trachtenberg and Pont, 1984), recently the abiraterone acetate (a potent inhibitor of the CYP17 $\alpha$-hydroxylase; De Bono et al., 2011) and Orteronel (TAK-700; Yamaoka et al., 2012).

\section{MUTATED OR PROMISCUOUS AR}

Androgen receptor genetic changes leading to aberrant functioning of the AR pathway may underlie the development of resistance to castration, allowing tumor cells to avoid the normal stimuli to growth. Largely, we are talking about somatic mutations in the AR gene, resulting in an increase of the potential ligands which bind and activate the AR receptor. The AR somatic mutation would include missense mutations like T877A and L701H. The T877A missense mutation has been described for the first time in LNCaP cell lines and affects the LBD of the AR. This alteration allows to ligands different from testosterone and DHT, such as progestins, estrogens, and antiandrogens to activate the AR. This may provide a molecular basis to "withdrawal syndrome" (i.e., patients treated with maximal androgen blockade, can benefit from the stop of antiandrogen (Kelly and Scher, 1993; Small and Srinivas, 1995). Zhao et al. (2000) described how the L701H mutation in conjunction with the T877A mutation of the LBD of the AR, could involve stimulating mutant cells growth by glucocorticoids (cortisone, cortisol). This may have important implications in clinical practice when you choose the glucocorticoid to be used in therapy.

\section{OVER-EXPRESSION OF AR CO-REGULATORS}

The AR activates its target gene transcription in response to the androgen stimulus. Its transactivation activities are modulated by co-regulators. Some evidences support the importance of co-regulators in the carcinogenesis and the development of hormone-resistance in PC. AR co-regulators consist of almost 200 proteins able to enhance (co-activators) or repress (co-repressors) the transcriptional activity of the AR. Genes mutation or the aberrant expression of this molecules may participate in PC progression (Gao et al., 2002). Several findings suggest that the NCOA2 gene (a nuclear receptor co-activator) would play the role of the potential oncogene in PC. Taylor et al. (2010) hypothesized that its amplification or mutation in primary and metastatic $\mathrm{PC}$ enhances the androgen-dependent AR transcriptional activity. The steroid receptor co-activator (SRC) family includes the SRC-1, the SRC-2, and the SRC-3. Literature shows that the SRC-1 is overexpressed in ADT-refractory PCs. Gregory et al. (2004) found that the SRC-2 is also over-expressed in recurrent PCs. This change may contribute to PC relapse after endocrine therapy. There is no clear evidence about the possible roles of the SRC-3 in prostate tumor development and progression. The steroid receptor RNA activator (SRA) is another co-activator for steroid receptors which functions as a RNA transcript in a ribonucleoprotein complex containing the SRC-1. Kawashima et al. (2002) showed that the SRA expression is higher in androgen-independent PC cell lines (PC-3) compared to the androgen-dependent ones (DU-145, LNCaP). The ARassociated protein ARA70 can interact with the AR and modulate its transcriptional activity in response to the androgens stimulation. It must also be reported that the ARA70 could facilitate the agonist activity of antiandrogens like bicalutamide (Miyamoto et al., 1998). In normal prostatic epithelium the ARA70 is highly expressed, while studies showed that the ARA70 expression was decreased or suppressed by methylation in androgen-dependent PC cell lines (DU145). Its expression seems to be regulated by both ER and AR in PC cells (Tekur et al., 2001).

\section{THE AR ACTIVATION BY CK AND GROWTH FACTORS}

The possibility of a cross-talk between the AR pathway and intracellular signaling cascades activated by IGF-1, KGF, and EGF, 
leading to transcription of androgen controlled genes, in the absence of the ligand exists (Culig etal., 1994). The ErbB or HER receptor network is frequently alterated in solid tumors. The HER kinase family includes: the epidermal growth factor receptor (EGFR or ErbB1), the human epidermal growth factor receptor 2 (HER2), the ErbB3 (HER3), and the ErbB4 (HER4). The HER2 is the only one in a fixed open conformation, other members need to bind to the ligand to form active dimer instead (Solit and Rosen, 2007). In breast cancers, the ErbB2 over-expression correlates with estrogen independence. In the ErbB2 over-expressed breast cancers therapy the antiHER2 monoclonal antibody, trastuzumab (Herceptin) can be used. Similar to the breast cancer case, or even in PC (Signoretti etal., 2000), it may exist a connection between the over-expression of the HER2/neu (also known as ErbB2) and the progression to castrate resistant disease. The activation of the HER2 signaling cascade may lead to constitutive activation of the AR (Craft etal., 1999; Yeh etal., 1999). Studies suggest that the ErbB receptor activation may be important in the growth and in the survival of both androgen-dependent and androgen-independent PC (Agus et al., 2002). In particular, the ErbB2-ErbB3 signaling has been implicated in enhancing the AR signaling through modulation of its transcriptional activity and its degradation in the presence of low androgen levels (Mellinghoff etal., 2004). Wen et al. (2000) showed in LNCaP cells that the HER2/neu activates Akt (protein kinase B) and in this way promotes the PC cells survival and growth in absence of androgens. These conditions may open new ways to PC therapy. However, when trastuzumab (Lara et al., 2004; Ziada et al., 2004) and pertuzumab (a second generation of anti-HER2 monoclonal antibody; De Bono et al., 2007), as well as the EGFR tyrosine kinase inhibitors (TKIs) gefitinib (Canil et al., 2005) and erlotinib (Gravis et al., 2006) have been tested in PC, it was observed a non-significant single-agent activity. These results suggest that these targets may be of secondary importance or of primary importance only in few cases of PC. According to the disappointing results obtained by the single use of these molecules, some researchers attempted to test them in combination. These therapeutic strategies aim to get the return of prostatic cancer cells to the androgen sensibility. Distinct phase II studies, show that three EGFR inhibitors have been combined with docetaxel. In single-arm studies of the gefitinib or erlotinib, PSA and tumor responses were modest, although the erlotinib showed favorable survival (24.6 months) with increased toxicity (Gross et al., 2007; Salzberg et al., 2007). Recent evidences also suggest that the HER-2 expression confers an increased risk of CNS metastases in the metastatic CRPC (Gernone et al., 2011). Other factors not directly related to the AR are certainly involved in the carcinogenesis and progression of PC. Data from some studies point to the potential role of proteins involved in the regulation of vascular permeability and endothelial proliferation. In 2006, a study shown that the endocrine gland-derived vascular endothelial growth factor/prokineticin 1 and 2 (EG-VEGF/PK1 and 2) and their receptors were expressed after the transition from benign to malignant prostatic glandular epithelium and that their levels increased with increasing histological grade (Pasquali et al., 2006).

\section{TREATMENT FOR CASTRATION-RESISTANT PROSTATE CANCER}

Currently, chemotherapy represents one of the possible treatment options in the setting of the CRPC, providing modest survival and palliative benefits. However, many other therapeutic options are now available. With the FDA approval of Docetaxel in 2004 prospects on the therapeutic possibilities for this type of cancer has gradually expanded. Docetaxel-based chemotherapy (given every 3 weeks at a dose of $75 \mathrm{mg} / \mathrm{m}^{2}$ along with a corticosteroid) as standard treatment in the CRPC is based on the survival advantage (approximately 3 months in median OS when compared with mitoxantrone and prednisone) observed in two independent phase III studies (TAX 327 trial and SWOG 99-16 trial). However, most men treated with this drug experienced progression of their disease within 1 year from the start of chemotherapy. Between 2010 and 2011 the cabazitaxel, the sipuleucel-T and the abiraterone acetate were also approved by the FDA for treatment of metastatic CRPC. In addition, a novel new bone-targeting monoclonal antibody, denosumab (Xgeva), and an LHRH antagonist, degarelix (Firmagon), have been introduced into clinical practice. Cabazitaxel is a microtubule inhibitor approved by FDA for the treatment of patients with CRPC progressed after docetaxel. Cabazitaxel, in a phase III multicenter study, in which it was compared with mitoxantrone, showed a statistically significant advantage in terms of median overall survival (15.1 vs. 12.7$)$ and PFS (2.8 vs. 1.4; De Bono et al., 2010). Also Abiraterone, in a phase III study, has been shown to improve the outcome of men progressing during or after a docetaxel-based chemotherapy treatment in which it prolonged the patients median survival to 4 months if compared to placebo (De Bono et al., 2011). Abiraterone (a potent and irreversible inhibitor of the CYP17A) is designed to treat the CRPC by inhibiting the production of androgen in the testis, in the adrenal glands, and in prostate tumor itself. Since there are no head-to-head comparisons to guide us in choosing between these two drugs, largely, patients for these therapies are selected according to the different side effect profile of these agents. One trial is currently ongoing looking at the comparison of abiraterone plus prednisone vs. placebo and prednisone in asymptomatic or mildly symptomatic metastatic CRPC who have not received chemotherapy. The Sipuleucel-T is an autologous cellular immunological agent, obtained by leukapheresis and cultured (activated) with a recombinant human protein (PAP-GM-CSF) consisting of prostatic acid phosphatase linked to the granulocyte-macrophage colony-stimulating factor, that shown to improve survival in minimally symptomatic patients. The Sipuleucel-T is thought to work through APCs to stimulate the T cell immune response targeted against the PAP, an antigen that is highly expressed in most PC cells. The mechanism for immunotherapy of PC, in general, is that cancer cells contain antigens of the prostate that can be recognized by the immune system (through the APC and T cells) allowing a selective killing of PC cells. T cells respond to small peptides derived from intracellular proteins and are present on specialized molecules on the surface of cancer cells. PC cells can be recognized by virtue of containing new proteins, formed as a result of mutations in somatic gene translocations, or to express proteins lineage, representing differentiation prostate cells (Kantoff et al., 2010a). Today new agents are being evaluated for men with 
metastatic CRPC in both first-line (in combination with docetaxel) and second-line treatment (in men progressing during or after treatment with docetaxel). Phase III clinical studies are ongoing on molecules with different targets: the androgen signaling pathway (MDV3100, Scher et al., 2010; TAK-700, Dreicer et al., 2010) has demonstrated significant activity in phase I and II studies), immunoregulatory pathways (Ipilimumab, the ProstvacVF-Tricom (Kantoff et al., 2010b), the Src (dasatinib; Araujo et al., 2009), the Met (cabozantinib), and the angiogenesis (aflibercept; Isambert et al., 2008, tasquinimod). Recently, attention has been paid to the possibility of radioimmunotherapy (RIT) use in PC. The prostate-specific membrane antigen (PSMA) is an integral cell-surface membrane protein and an ideal target for monoclonal antibody therapy. The anti-PSMA monoclonal antibody radionuclide labeled (J591) has been studied in phase I and II studies. The most common radionuclides used have been 90-Yttrium and 177-Lutetium. This trials seem to suggest that the radiolabeled J591 has antitumor activity and is well tolerated. Phase I trial on chemotherapy and RIT combination is also ongoing (Milowsky et al., 2004; Bander et al., 2005; Tagawa et al., 2008, 2010). However, resistance to the first-line chemotherapy occurs, inevitably, even in patients who initially responded. Studies were designed in order to overcome this obstacle in different ways. Some researchers attempted associating docetaxel to a molecule able to interfere with one or more mechanisms of chemotherapy resistance. The aim is to improve the efficiency of a well-known cytotoxic agent to carry out its task. On the basis of encouraging results of a phase II trial, Chi et al. (2009) employed this strategy in a phase III study

\section{REFERENCES}

Agus, D. B., Akita, R. W., Fox, W. D. Lewis, G. D., Higgins, B., Pisacane, P. I., et al. (2002). Targeting ligandactivated ErbB2 signaling inhibits breast and prostate tumor growth. Cancer Cell 2, 127-137.

American Cancer Society. (2012). Cancer Facts \& Figures 2012. Atlanta: American Cancer Society.

Araujo, J., Armstrong, A. J., Braud, E. L., Posadas, E., Lonberg, M., Gallick, G. E., et al. (2009). Dasatinib and docetaxel combination treatment for patients with castration-resistant progressive prostate cancer: a phase I/II study (CA180086). J. Clin. Oncol. 27(Suppl.), 249s, abstr. 5061.

Bander, N. H., Milowsky, M. I., Nanus, D. M., Kostakoglu, L., Vallabhajosula, S., and Goldsmith, S. J. (2005). Phase I trial of 177Lutetium-labeled J591, a monoclonal antibody to prostate-specific membrane antigen, in patients with androgen-independent prostate cancer. Cancer 23, 4591-4601.

Berger, S., Kouzarides, T., Shiekhattar, R., and Shilatifard, A. (2009). An operational definition of epigenetics. Genes Dev. 23, 781-783.

Cairns, P., Okami, K., Halachmi, S., Halachmi, N., Esteller, M., Herman,
J. G., et al. (1997). Frequent inactivation of PTEN/MMAC1 in primary prostate cancer. Cancer Res. 57, 4997-5000.

Canil, C. M., Moore, M. J., Winquist, E., Baetz, T., Pollak, M., Chi, K. N., et al. (2005). Randomized phase II study of two doses of gefitinib in hormone-refractory prostate cancer: a trial of the National Cancer Institute of Canada-Clinical Trials Group. J. Clin. Oncol. 23, 455-460.

Chi, K. N., Hotte, S. J., Yu, E., Tu, D., Eigl, B., Tannock, I., et al. (2009). Mature results of a randomized phase II study of OGX-011 in combination with docetaxel/prednisone versus docetaxel/prednisone in patients with metastatic castration-resistant prostate cancer. J. Clin. Oncol. 27(Suppl.), 238s, abstr. 5012.

Chin, S. P., Dickinson, J. L., and Holloway, A. F. (2011). Epigenetic regulation of prostate cancer. Clin. Epigenet. 2, 151-169.

Craft, N., Shostak, Y. Carey, M., and Sawyers, C. L. (1999). A mechanism for hormone-independent prostate cancer through modulation of androgen receptor signaling by the HER-2/ neu tyrosine kinase. Nat. Med. 5, 280-285.

using the antisense oligonucleotide: the custirsen (OGX-011). Evidences in literature also indicate that tumor microenvironment may be critically implicate in PC therapy resistance. In particular angiogenic growth factors like vascular endothelial growth factor (VEGF) may have a crucial role in mechanisms guiding bone metastatization and disease progression. So recently attention has been paid to the use of docetaxel in conjunction with stroma-targeting molecules.

\section{CONCLUSION}

Nowadays treatment options available for the CRPC are many and new questions emerge. First, how these new drugs have to be administered in clinical practice. In the era of the personalized cancer therapies, the deep knowledge of underlying mechanisms of the castration resistance of PC has become a topic of primary importance. Research in this field aims to obtain the tools in order to choose the most effective and less toxic therapy for each patient. This is more evident if we think about the impact of the hormone therapy on patients with PC quality life. In this way risks and benefits, ratio of a single therapy, have a greater significance. New biomarkers able to predict which patients may really benefit from a specific therapy without being exposed to an unnecessary toxicity, are required. For the future it should be possible to understand the genetic background of our patients with regard to some critical enzymes which could influence both response and resistance to drugs, before starting a specific therapy. This chance could make it really feasible to personalize the therapy in individual patients.

Crawford, E. D. (1992). Challenges in the management of prostate carcinoma. Br. J. Urol. 70(Suppl. 1), 33-38.

Culig, Z., Hobisch, A., Cronauer, M. V., Radmayr, C., Trapman, J., Hittmair, A., et al. (1994). Androgen receptor activation in prostatic tumor cell lines by insulin-like growth factor-1, keratinocyte growth factor, and epidermal growth factor. Cancer Res. 54, 5474-5478.

De Bono, J., Bellmunt, J., Attard, G., Droz, J. P., Miller, K., Flechon, A., et al. (2007). An open-label phase II study evaluating the efficacy and safety of two doses of pertuzumab in castrate chemotherapy-naive patients with hormone-refractory prostate cancer. J. Clin. Oncol. 25, 257-262.

De Bono, J. S., Logothetis, C. J., Molina, A., Fizazi, K., North, S., Chu, L., et al. (2011). Abiraterone and increased survival in metastatic prostate cancer. N. Engl. J. Med. 364, 1995-2005.

De Bono, J. S., Oudard, S., Ozguroglu, M., Hansen, S., Machiels, J. P., Kocak, I., et al. (2010). Prednisone plus cabazitaxel or mitoxantrone for metastatic castration-resistant prostate cancer progressing after docetaxel treatment: a randomized openlabel trial. Lancet 376, 1147-1154.
Dreicer, R., Agus, D. B., Mac Vicar, G. R., MacLean, D., Zhang, T., Stadler, W. M., et al. (2010). Safety, pharmacokinetics, and efficacy of TAK700 in metastatic castration-resistant prostate cancer: a phase I/II, openlabel study. J. Clin. Oncol. 28(Suppl.), 18 s, abstr. 3084.

Feldman, B. J., and Feldman, D. (2001). The development of androgen-independent prostate cancer. Nature 34, 1.

Ferlay, J., Shin, H. R., Bray, F., Forman, D., Mathers, C., and Parkin, D. M. (2010). GLOBOCAN2008, Cancer Incidence and Mortality Worldwide: IARC Cancer Case No. 10 [Internet]. Lyon: International Agency for Research on Cancer. Available at: http://globocan.iarc.fr

Gao, X., Loggie, B. W., and Newaz, Z. (2002). The roles of sex steroid receptor coregulators in cancer. Mol. Cancer 1, 7.

Gernone, A., Pagliarulo, A., Trabucco, S., and Pagliarulo, V. (2011). Correlation between HER2 status and central nervous system (CNS) involvement in metastatic castrationresistant prostate cancer (mCRPC). J. Clin. Oncol. 29(Suppl.), abstr. e15190.

Gravis, G., Goncalves, A., Bladou, F., Salem, N., Esterni, B., Bagattini, S., 
etal. (2006). "A phase II study of erlotinib in advanced prostate cancer," in American Society of Clinical Oncology - Prostate Cancer Symposium 2006, February 24-26, 2006, San Francisco, California, abstr. 216.

Gregory, C. W., Johnson, R. T. Jr., Mohler, J. L., French, F. S., Wilson, E. M., et al. (2004). Androgen receptor stabilization in recurrent prostate cancer is associated with hypersensitivity to low androgen. Cancer Res. 61, 2892-2898.

Gross, M., Higano, C., Pantuck, A., Castellanos, O., Green, E., Nguyen, K., etal. (2007). A phase II trial of docetaxel and erlotinib as firstline therapy for elderly patients with androgen-independent prostate cancer. BMC Cancer 7, 142. doi: 10.1186/1471-2407-7-142

Gu, K., Mes Masson, A. M., Gauthier, J., and Saad, F. (1998). Analysis of the p16 tumor suppressor gene in earlystage prostate cancer. Mol. Carcinog. 21, 164-170.

Helcomb, I. N., Young, J. M., Coleman, I. M., Salari, K., Grove, D. I., Hsu, L., et al. (2009). Comparative analyses of chromosome alterations in soft-tissue metastases within and across patients with castrationresistant prostate cancer. Cancer Res. 69, 7793-7802

Hobisch, A., Culig, Z., Radmayr, C., Bartsch, G., Klocker, H., and Hittmair, A. (1995). Distant metastases from prostatic carcinoma express androgen receptor protein. Cancer Res. 55, 3068-3072.

Huggins, C., and Hodges, C. V. (2002). Studies on prostatic cancer: the effect of castration, of estrogen and of androgen injection on serum phosphatases in metastatic carcinoma of the prostate. 1941. J. Urol. 168, 9-12.

Hulett, M. D., Freeman, C., Hamdorf, B. J., Baker, R. T., Harris, M. J., and Parish, C. R. (1999). Cloning of mammalian heparanase, an important enzyme in tumor invasion and metastasis. Nat. Med. 5, 803-809.

Isambert, N., Freyer, G., Zanetta, S., Falandry, C., Soussan Lazard, K., Fumoleau, P., et al. (2008). A phase I dose escalation and pharmacokinetic (PK) study of intravenous aflibercept (VEGF trap) plus docetaxel in patients with advanced solid tumors: preliminary results. J. Clin. Oncol. 26(Suppl.), 177s, abstr. 3599.

Jarrard, D. F., Bova, J. S., Ewing, C. M., Pin, S. S., Nguyen, S. H., Baylin, S. B., etal. (1997). Deletional, mutational, and methylation analyses of CDKN2 (p16/MTS1) in primary and metastatic prostate cancer. Genes Chromosomes Cancer 19, 90-96.

Kang, G. H., Lee, S., Lee, H. J., and Hwang, K. S. (2004). Aberrant CpG island hypermethylation of multiple genes in prostate cancer and prostatic intraepithelial neoplasia. J. Pathol. 64, 1975-1986.

Kantoff, P. W., Higano, C. S., Shore, N. D., Berger, E. R., Small, E. J., Penson, D. F., et al. (2010a). Sipuleucel$\mathrm{T}$ immunotherapy for castrationresistant prostate cancer. N. Engl. J. Med. 363, 411-422.

Kantoff, P. W., Schuetz, T. J., Blumenstein, B. A., Glode, L. M., Bilhartz, D. L., Wyand M., et al. (2010b). Overall survival analysis of a phase II randomized controlled trial of a poxviralbased PSA-targeted immunotherapy in metastatic castration-resistant prostate cancer. J. Clin. Oncol. 28, 1099-1105.

Kawashima, H., Takano, H., Sugita, S., Sugimura, K., and Nakatani, T. (2002). A novel steroid receptor co-activator protein (SRAP) as an alternative form of steroid receptor RNA-activator gene: expression in prostate cancer cells and enhancement of androgen receptor activity. Biochem. J. 369(Pt 1), 163-171.

Kelly, W. K., and Scher, H. I. (1993). Prostate specific antigen decline after antiandrogen withdrawal: the flutamide withdrawal syndrome. J. Urol. 149, 607-609.

Koivisto, P., Kononen, J., Palmberg, C., Tammela, T., Hyytinen, E., Isola, J., et al. (1997). Androgen receptor gene amplification: a possible molecular mechanism for androgen deprivation therapy failure in prostate cancer. Cancer Res. 57, 314-319.

Labrie, F. (2004). Adrenal androgens and intracrinology. Semin. Reprod. Med. 22, 299-309.

Labrie, F., Dupont, A., Bélanger, A., St-Arnaud, R., Giguère, M., Lacourcière, Y., et al. (1986). Treatment of prostate cancer with gonadotropinreleasing hormone agonists. Endocr. Rev. 7, 67-74.

Lara, P. N. Jr., Chee, K. G., Longmate, J., Ruel, C., Meyers, F. J., Gray, C. R., et al. (2004). Trastuzumab plus docetaxel in HER-2/neu-positive prostate carcinoma: final results from the California Cancer Consortium Screening and Phase II Trial. Cancer 100, 2125-2131.

Lee, W. H., Morton, R. A., Epstein, J. I., Brooks, J. D., Campbell, P. A., Bova, G. S., et al. (1994). Cytidine methylation of regulatory sequences near the pi-class glutathione s-transferase gene accompanies human prostatic carcinogenesis. Proc. Natl. Acad. Sci. U.S.A. 91, 11733-11737.

Li, L. C., Zhao, H., Nakajima, K., Oh, B. R., Ribeiro Filhho, L. A., and Carroll, P. (2001). Methylation of the E-cadherin gene promoter correlates with progression of prostate cancer. $J$. Urol. 166, 705-709.

Liu, J., Geller, J., Albert, J., and Kirshner, M. (1985). Acute effects of testicular and adrenal cortical blockade on protein synthesis and dihydrotestosterone content of human prostate tissue. J. Clin. Endocrinol. Metab. 61, 129-133.

Locke, J. A., Guns, E. S., Lubik, A. A., Adomat, H. H., Hendy, S. C., Wood, C. A., et al. (2008). Androgen levels increase by intratumoral de novo steroidogenesis during progression of castration-resistant prostate cancer. Cancer Res. 68, 6407-6415.

Lonergan, P. E., and Tindall, D. J. (2011). Androgen receptor signaling in prostate cancer development, and progression. J. Carcinog. 10, 20.

Mackinnon, A. C., Yan, B. C., Joseph, L. J., Al-Ahmadie, H. A., et al. (2009). Molecular biology underlying the clinical heterogeneity of prostate cancer. Arch. Pathol. Lab. Med. 133, 1033-1040.

Makridakis, N., Ross, R. K., Pike, M. C., Chang, L., Stanczyk, F. Z., Kolonel, L. N., et al. (1997). A prevalent missense substitution that modulates activity of prostatic steroid $5 \alpha$-reductase. Cancer Res. 57, 1020-1022.

Marcelli, M., Ittmann, M., Mariani, S., Sutherland, R., Nigam, R., Murthy, L., et al. (2000). Androgen receptor mutations in prostate cancer. Cancer Res. 60, 944-949.

Mellinghoff, I. K., Vivanco, I., Kwon, A., Tran, C., Wongvipat, J., Sawyers, C. L., et al. (2004). HER2/neu kinasedependent modulation of androgen receptor function through effects on DNA binding and stability. Cancer Cell 6, 517-527.

Milowsky, M. I., Nanus, D. M., Kostakoglu, L., Vallabhajosula, S. Goldsmith, S. J., and Bander, N. H. (2004). Phase I trial of yttrium-90labeled anti-prostate-specific membrane antigen monoclonal antibody J591 for androgen-independent prostate cancer. J. Clin. Oncol. 22, 2522-2531.

Miyamoto, H., Yeh, S., Wilding, G., and Chang, C. (1998). Promotion of agonist activity of antiandrogens by the androgen receptor coactivator, ARA70, in human prostate cancer DU145 cells. Proc. Natl. Acad. Sci. U.S.A. 95, 7379-7384.

Montgomery, R. B., Mostaghel, E. A., Vessella, R., Hess, D. L., Kalhorn, T.
F., Higano, C. S., et al. (2008). Maintenance of intratumoral androgens in metastatic prostate cancer: a mechanism of castration-resistant tumor growth. Cancer Res. 68, 4447-4454.

Nakayama, M., Bennett, C. J., Hicks, J. L., Epstein, J. I., Platz, E. A., Nelson, W. G., et al. (2003). Hypermethylation of the human glutathione $S$-transferase- $\pi$ gene (GSTP1) CpG island is present in a subset of proliferative inflammatory atrophy lesions but not in normal or hyperplastic epithelium of the prostate: a detailed study using laser-capture microdissection. Am. J. Pathol. 163, 923-933.

Nelson, W. G., Carter, B., DeWeese, T. L., and Eisenberger, M. A. (2008). "Prostate cancer," in Clinical Oncology, 4th Edn., Vol. 2, eds M. D. Abeloff, J. O. Armitage, A. S. Lichter, J. E. Niederhuber, M. B. Kastan, and W. G. McKenna (Philadelphia, PA: Elsevier), 1656-1657.

Pakneshan, P., Xing, R., and Rabbani, S. (2003). Methylation status of uPA promoter as a molecular mechanism regulating prostate cancer invasion and growth in vitro and in vivo. FASEB J. 17, 1081-1088.

Palmberg, C., Koivisto, P., Kakkola, L., Tammela, T. L., Kallioniemi, O. P., and Visakorpi, T. (2000).Androgen receptor gene amplification at primary progression predict response to combined androgen blockade as second line therapy for advanced prostate cancer. J. Urol. 164, 19921995.

Pasquali, D., Rossi, V., Staibano, S., De Rosa, G., Chieffi, P., Prezioso, D., et al. (2006). The endocrine-glandderived vascular endothelial growth factor (EG-VEGF)/prokineticin 1 and 2 and receptor expression in human prostate: up-regulation of EG-VEGF/prokineticin 1 with malignancy. Endocrinology 147, 42454251.

Ruijter, E., van de Kaa, C., Miller, G., Ruiter, D., Debruyne, F., and Schalken, J. (1999). Molecular genetics and epidemiology of prostate carcinoma. Endocr. Rev. 20, 22-45.

Salzberg, M., Rochlitz, C., Morant, R., Thalmann, G., Pedrazzini, A., Roggero, E., et al. (2007). An open-label, noncomparative phase II trial to evaluate the efficacy and safety of docetaxel in combination with gefitinib in patients with hormone-refractory metastatic prostate cancer. Onkologie 30, 355-360.

Scher, H. I., Beer, T. M., Higano, C. S., Anand, A., Taplin, M. E., Efstathiou, E., et al. (2010). Antitumour activity of MDV3100 in castration-resistant 
prostate cancer: a phase 1-2 study. Lancet 375, 1437-1446.

Signoretti, S., Montironi, R., Manola, J., Altimari, A., Tam, C., Bubley, G., et al. (2000). Her-2-neu expression and progression toward androgen independence in human prostate cancer. J. Natl. Cancer Inst. 92, 1918-1925.

Small, E. J., and Srinivas, S. (1995). The antiandrogen withdrawal syndrome. Experience in a large cohort of unselected patients with advanced prostate cancer. Cancer 76, 14281434.

Solit, D. B., and Rosen, N. (2007). Targeting HER2 in prostate cancer: where to next? J. Clin. Oncol. 25, 241-243.

Steers, W. D. (2001). 5alpha-reductase activity in the prostate. Urology 58(Suppl. 1), 17-24.

Suzuki, H., Freije, D., Nusskern, D. R., Okami, K., Cairns, P., Sidransky, D., et al. (1998). Interfocal heterogeneity of PTEN/MMAC1 gene alterations in multiple metastatic prostate cancer tissues. Cancer Res. 58, 204-209.

Suzuki, H., Ueda, T., Ichikawa, T., and Ito, H. (2003). Androgen receptor involvement in the progression of prostate cancer. Endocr. Relat. Cancer 10, 209-216

Tagawa, S. T., Beltran, H., Vallabhajosula, S., Goldsmith, S. J., Osborne, J., Matulich, D., et al. (2010). Anti-prostate-specific membrane antigen-based radioimmunotherapy for prostate cancer. Cancer 116, 1075-1083.

Tagawa, S. T., Milowsky, M. I., Morris, M., Vallabhajosula, S., Goldsmith, S., Matulich, D., et al. (2008). Phase
II trial of 177Lutetium radiolabeled anti-prostate-specific membrane antigen (PSMA) monoclonal antibody J591 (177Lu-J591) in patients (pts) with metastatic castrateresistant prostate cancer (metCRPC). J. Clin. Oncol. 26(Suppl.), 284s.

Taplin, M. E., Bubley, G. J., Shuster T. D., Frantz, M. E., Spooner, A. E. Ogata, G. K., et al. (1995). Mutation of the, androgen receptor gene in metastatic, androgen-independent prostate cancer. N. Engl. J. Med. 332, 1393-1398.

Taylor, B. S., Schultz, N., Hieronymus, H., Gopalan, A., Xiao, Y., Carver, B. S., et al. (2010). Integrative genomic profiling of human prostate cancer. Cancer Cell 18, 11-22.

Tekur, S., Lau, K. M., Long, J., Burnstein, K., and Ho, S. M. (2001). Expression of RFG/ELE I alpha/ARA70 in normal and malignant prostatic epithelial cell cultures and lines: regulation by methylation and sex steroids. Mol. Carcinog. 30, $1-13$.

Titus, M. A., Gregory, C. W., Ford, O. H. III, Schell, M. J., Maygarden, S. J., and Mohler, J. L. (2005). Steroid 5alpha-reductase isozymes I and II in recurrent prostate cancer. Clin. Cancer Res. 11, 4365-4371.

Tomlins, S. A., Rhodes, D. R., Perner, S., Dhanasekaran, S. M., Mehra, R., Sun, X. W., et al. (2005). Recurrent fusion of TMPRSS2 and ETS transcription factor genes in prostate cancer. Science 310, 644-648.

Trachtenberg, J. J., and Pont, A. A. (1984). Ketoconazole therapy for advanced prostate cancer. Lancet 2, 433-435. van der Kast, T. H., Schalken, J., Ruizeveld de Winter, J. A., van Vroonhoven, C. C., Mulder, E., Boersma, W., et al. (1991). Androgen receptor in endocrine therapy resistant human prostate cancer. Int. J. Cancer 48, 189-193.

Wang, F., Zou, Y. F., Feng, X. L., Su, H., and Huang, F. (2011). CYP17 gene polymorphisms and prostate cancer risk: a meta-analysis based on 38 independent studies. Prostate 71 1167-1177.

Wen, Y., Hu, M. C., Makino, K., Spohn, B., Bartholomeusz, G., Yan, D. H., et al. (2000). HER-2/neu promotes androgen-independent survival and growth of prostate cancer cells through the Akt pathway. Cancer Res. 60, 6841-6845.

Wright, J. L., Kwon, E. M., Lin, D. W., Kolb, S., Koopmeiners, J. S., Feng, Z., et al. (2010). CYP17 polymorphisms and prostate cancer outcomes. Prostate 70, 1094 1101.

Yamaoka, M., Hara, T., Hitaka, T., Kaku, T., Takeuchi, T., Takahashi, J., et al. (2012). Orteronel (TAK-700), a novel non-steroidal 17,20-lyase inhibitor: effects on steroid synthesis in human and monkey adrenal cells and serum steroid levels in cynomolgus monkeys. J. Steroid Biochem. Mol. Biol. 129, 115-128.

Yeh, S., Lin, H. K., Kang, H. Y., Thin, T. H., Lin, M. F., and Chang, C. (1999). From HER2/Neu signal cascade to androgen receptor and its coactivators: a novel pathway by induction of androgen target genes through MAP kinase in prostate cancer cells. Proc. Natl. Acad. Sci. U.S.A. 96, 5458-5463.
Zhao, X. Y., Malloy, P. J., Krishnan, A. V., Swami, S., Navone, N. M., Peehl, D. M., et al. (2000). Glucocorticoids can promote androgen independent growth of prostate cancer cells through a mutated androgen receptor. Nat. Med. 6, 703-706.

Ziada, A., Barqawi, A., Glode, L. M., Varella-Garcia, M., Crighton, F., Majeski, S., et al. (2004). The use of trastuzumab in the treatment of hormone refractory prostate cancer: phase II trial. Prostate 60, 332-337.

Conflict of Interest Statement: The authors declare that the research was conducted in the absence of any commercial or financial relationships that could be construed as a potential conflict of interest.

Received: 18 April 2012; accepted: 10 October 2012; published online: 06 November 2012.

Citation: Aschelter AM, Giacinti S, Caporello $P$ and Marchetti P (2012) Genomic and epigenomic alterations in prostate cancer. Front. Endocrin. 3:128. doi: 10.3389/fendo.2012.00128

This article was submitted to Frontiers in Cancer Endocrinology, a specialty of Frontiers in Endocrinology.

Copyright (C) 2012 Aschelter, Giacinti, Caporello and Marchetti. This is an openaccess article distributed under the terms of the Creative Commons Attribution License, which permits use, distribution and reproduction in other forums, provided the original authors and source are credited and subject to any copyright notices concerning any third-party graphics etc. 